\title{
Incidence of airway complications associated with deep extubation in adults
}

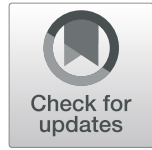

Jeremy Juang ${ }^{1,2^{*}}$ (D), Martha Cordoba ${ }^{1,2+}$, Alex Ciaramella ${ }^{1,2}$, Mark Xiao ${ }^{1,2}$, Jeremy Goldfarb ${ }^{1,2}$, Jorge Enrique Bayter ${ }^{3}$ and Alvaro Andres Macias ${ }^{1,2}$

\begin{abstract}
Background: Endotracheal extubation is the most crucial step during emergence from general anesthesia and is usually carried out when patients are awake with return of airway reflexes. Alternatively, extubations can also be accomplished while patients are deeply anesthetized, a technique known as "deep extubation", in order to provide a "smooth" emergence from anesthesia. Deep extubation is seldomly performed in adults, even in appropriate circumstances, likely due to concerns for potential respiratory complications and limited research supporting its safety. It is in this context that we designed our prospective study to understand the factors that contribute to the success or failure of deep extubation in adults.
\end{abstract}

Methods: In this prospective observational study, 300 patients, age $\geq 18$, American Society of Anesthesiologists Physical Status (ASA PS) Classification I - III, who underwent head-and-neck and ocular surgeries. Patients' demographic, comorbidity, airway assessment, $\mathrm{O}_{2}$ saturation, end tidal $\mathrm{CO}_{2}$ levels, time to exit $\mathrm{OR}$, time to eye opening, and respiratory complications after deep extubation in the OR were analyzed.

Results: Forty (13\%) out of 300 patients had at least one complication in the OR, as defined by persistent coughing, desaturation $\mathrm{SpO}_{2}<90 \%$ for longer than 10s, laryngospasm, stridor, bronchospasm and reintubation. When comparing the complication group to the no complication group, the patients in the complication group had significantly higher BMI (30 vs 26), lower $\mathrm{O}_{2}$ saturation pre and post extubation, and longer time from end of surgery to out of $\mathrm{OR}(p<0.05)$.

Conclusions: The complication rate during deep extubation in adults was relatively low compared to published reports in the literature and all easily reversible. BMI is possibly an important determinant in the success of deep extubation.

Keywords: Tracheal extubation, Deep extubation, Airway, Anesthesia, Ambulatory surgery, Emergence, Complications, Adult, Volatile anesthetics

\footnotetext{
* Correspondence: jeremy_juang@meei.harvard.edu

†Jeremy Juang and Martha Cordoba contributed equally to this work.

'Department of Anesthesiology, Massachusetts Eye and Ear, 243 Charles St,

Boston, MA 02114, USA

${ }^{2}$ Harvard Medical School, Boston, MA 20114, USA

Full list of author information is available at the end of the article
}

(C) The Author(s). 2020 Open Access This article is licensed under a Creative Commons Attribution 4.0 International License, which permits use, sharing, adaptation, distribution and reproduction in any medium or format, as long as you give appropriate credit to the original author(s) and the source, provide a link to the Creative Commons licence, and indicate if changes were made. The images or other third party material in this article are included in the article's Creative Commons. licence, unless indicated otherwise in a credit line to the material. If material is not included in the article's Creative Commons licence and your intended use is not permitted by statutory regulation or exceeds the permitted use, you will need to obtain permission directly from the copyright holder. To view a copy of this licence, visit http://creativecommons.org/licenses/by/4.0/ The Creative Commons Public Domain Dedication waiver (http://creativecommons.org/publicdomain/zero/1.0/) applies to the data made available in this article, unless otherwise stated in a credit line to the data. 


\section{Background}

Endotracheal extubation is the final and arguably the most crucial step during emergence from general anesthesia (GA). Normally, it is carried out when patients are awake with return of airway reflexes. However, extubations can also be accomplished while patients are deeply anesthetized but maintaining spontaneous breathing, a technique known as "deep extubation". Deep extubation is frequently performed in the setting of eye surgery as well as head and neck surgery. The intention is to minimize bucking and limit increase in intraocular and intracranial pressure [1-4].

When surveyed, even in appropriate clinical situations, many anesthesiologists are still reluctant to perform deep extubation in adults because of concerns for potential respiratory complications [5]. This apprehension may be unfounded as most published experiences (and reported complications) center around pediatric patients [6-9] and not adult patients. To our knowledge, there have only been a couple of adult deep extubation studies, with around 30 patients in each arm, comparing respiratory complications in patients deeply extubated after inhaled anesthetics with and without adjuvants [10, 11]. More robust data in a larger adult population are needed to inform clinical practice.

Therefore, in this prospective observational cohort study, we set out to assess the rate of respiratory complications after deep extubation in a larger sample size of 300 adult patients undergoing ocular and head and neck surgery. Our goal was to determine if there are intraoperative factors that may influence the success of deep extubations.

\section{Methods}

\section{Study population}

This single arm, unblinded, observational study was approved by the Institutional Review Board (IRB) of Massachusetts Eye and Ear Infirmary, Boston, Massachusetts (\#1047249). The study was conducted in accordance with all rules and regulations laid out by the IRB and human studies committee. A waiver of written informed consent was obtained for this study. This study was registered at Clinicaltrials.gov (NCT04557683).

Patients greater than 18 years of age at the time of surgery and selected by the anesthesiologist as a candidate for deep extubation were enrolled in this study without specific exclusion criterion. All patients were evaluated by the preoperative anesthesia staff prior to surgery and a detailed preoperative note detailing vital signs, health history, and airway assessment (Mallampati score I-IV, neck ROM, TM distance, mouth opening, and artificial airway, facial hair, dental exam) was documented in the electronic medical record. Over the course of six months, 300 patients were enrolled in this observational study. Each day during this six-month period, a research coordinator would report to the main operating room and determine the possible candidates for the day based on age and anesthetic plan. Towards the end of each surgery the research coordinator would ask each anesthesiologist utilizing inhalation anesthetics about the extubation plan. If the anesthesiologist selects the patient for deep extubation, the patient would be followed from the end of surgery to Post Anesthesia Care Unit (PACU) for data collection. The deep extubation technique was the only controlled procedural variable among our patient cohort; other anesthesia procedural variables were selected at the provider's discretion.

\section{Anesthetic management}

At the end of the case, the fraction of inspired oxygen $\left(\mathrm{FiO}_{2}\right)$ was increased to $100 \%$ and the end inspired concentration of inhaled anesthetic was adjusted to be at least 1 Minimum Alveolar Concentration (MAC) or higher if needed. The depth of anesthesia was considered adequate clinically when the patient was spontaneously breathing with a regular pattern, at a MAC of 1 or higher, and if the patient did not exhibit any response to suctioning and to deflation and reinflation of the endotracheal tube cuff. Before extubation, an oral airway was placed in all the patients, and jaw thrust was applied if needed after extubation. The oral airway was removed, either in the operating room by anesthesia provider or in PACU by trained PACU nursing staff with 1-to-1 nurse to patient ratio under the supervision of an anesthesiologist, when the patient regained airway reflexes. Patients were administered oxygen at $6 \mathrm{~L} / \mathrm{min}$, via a face mask; supplemental oxygen was discontinued in PACU as per usual recovery room management.

\section{Statistical analysis}

For comparison, patients were classified into two groups: those without respiratory complications to those with respiratory complications as defined by persistent coughing, desaturation measured by saturation of peripheral oxygen $\left(\mathrm{SpO}_{2}\right)$ by pulse oximetry of less than $90 \%$ for longer than 10s, laryngospasm, stridor, bronchospasm, and reintubation. Patient demographics, baseline characteristics, procedures, intubation notes, and intraoperative variables were obtained from the electronic medical records and analyzed. Statistical analysis and graphs were performed and presented using Prism 8.4.2 (GraphPad Software Inc., La Jolla, CA). The normality of the distribution of continuous variables was assessed using the Shapiro-Wilk normality test. Mann-Whitney tests were used to compare continuous variables among groups. A 2-tailed $P$-value less than 0.05 was considered significant. Fisher's exact test was used to compare categorical variables among groups. Continuous variables are presented 
as median with interquartile ranges (q1-q3), while categorical variables are summarized using frequencies and percentages.

\section{Results}

A total of 300 adult patients were recruited for the study. Among them, 40 (13\%) patients had at least one complication in the OR post deep extubation that included persistent coughing, desaturation $\mathrm{SpO}_{2}<90 \%$ for longer than 10s, sore throat, laryngospasm, stridor, bronchospasm (Fig. 1a). None of the 300 patients required re-intubation.

When comparing patient's demographic of the complications group to the no complications group, there were no differences in patient age (50.0(34.4-60.5) vs 50.0(30.3-52.0), $p=0.9506$ ) (Fig. 1b) and sex (Fig. 1c). In contrast, patients in the complications group had significantly higher BMI (30.0(25.3-35.0) vs 26.0(23.0-29.0), $p<0.0001)$ when compared to the no complications group (Fig. 1d).

We observed no significant difference in patient ASA PS classification or type of surgery class (ear, eye, neck, nose, throat, thyroid) (Fig. 2 a\&b). Furthermore, there were no significant differences in rates of pre-existing respiratory pathology, Mallampati Score, Cormack and Lehane's classification between complications and nocomplications groups (Fig. 2c-e). Lastly, all the patienta were able to be masked.

\section{A Number of Complications}

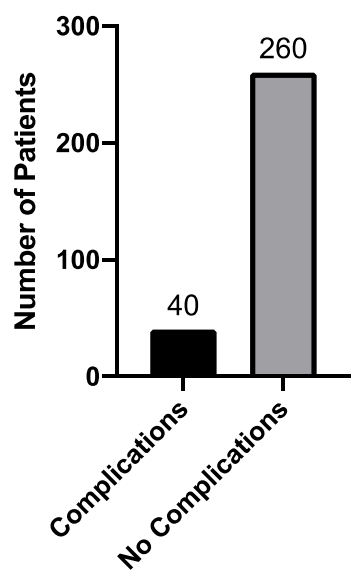

C

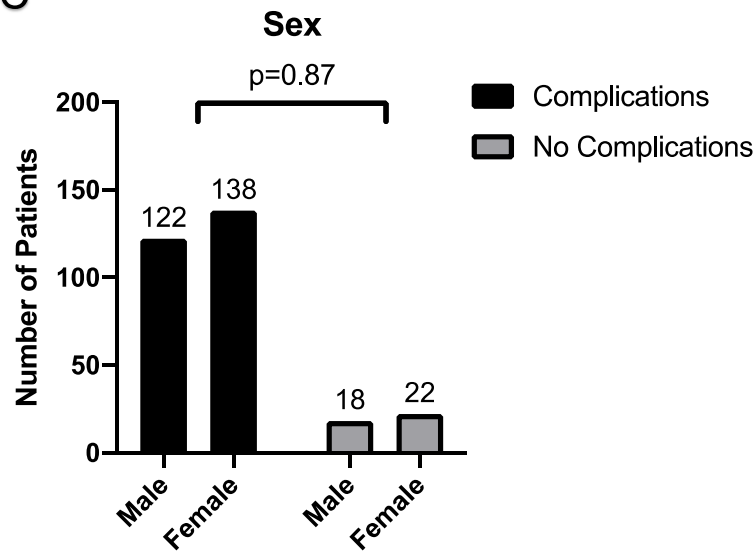

B

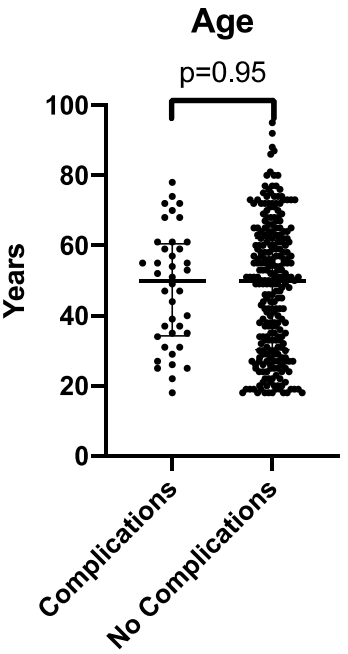

D

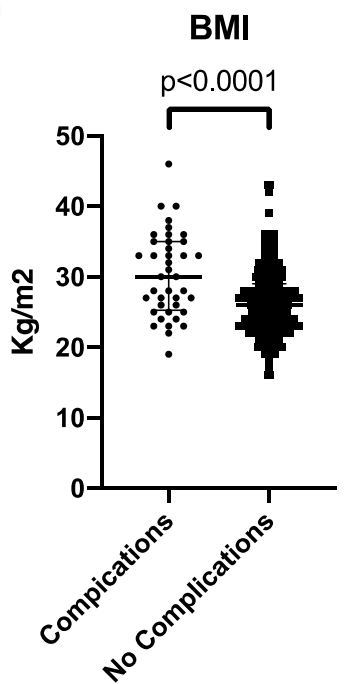

Fig. 1 Number of patients with at least one complication ${ }^{*}$ in the OR after deep extubation (a) and comparison of patient demographics between complications and no complications group by (b) Age, (c) BMI, and (d) Sex. ${ }^{*}$ Complications include desaturation SpO2 < $90 \%$ for longer than 10 s, persistent cough, laryngospasm, stridor, bronchospasm, and reintubation 


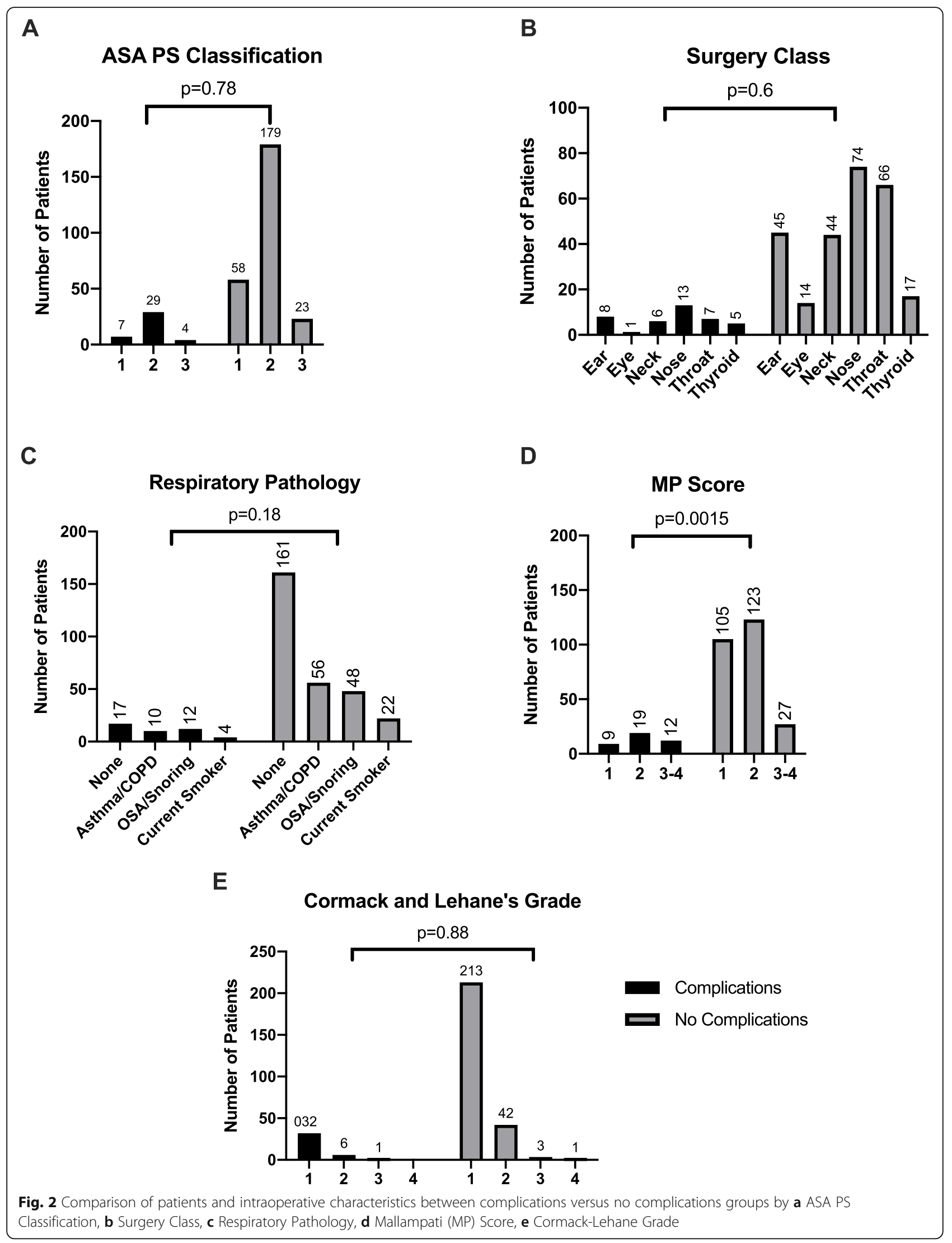


A

\section{MAC at Extubation}

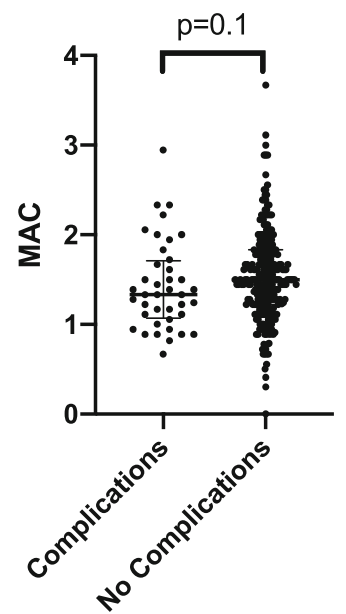

C
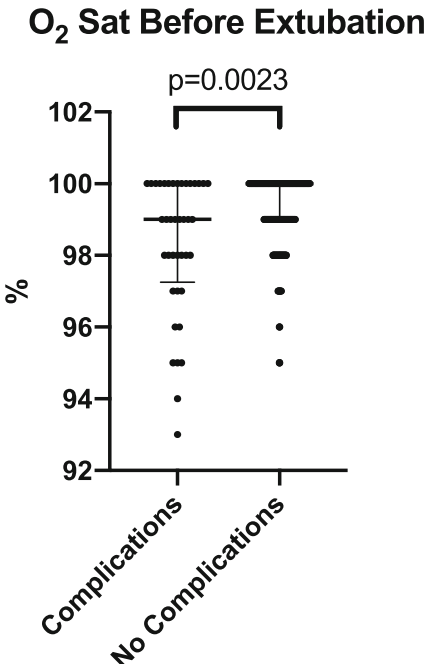

B

etCO ${ }_{2}$ at Extubation

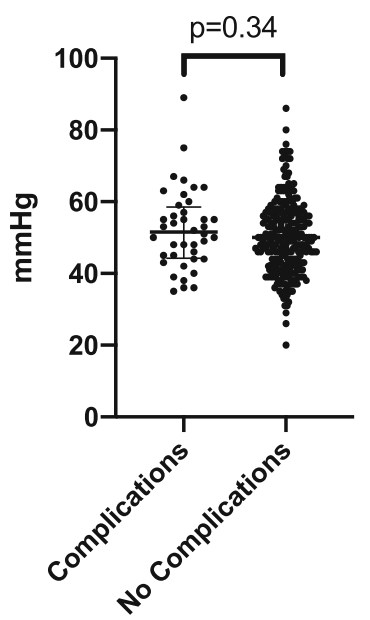

D

$\mathrm{O}_{2}$ Sat After Extubation

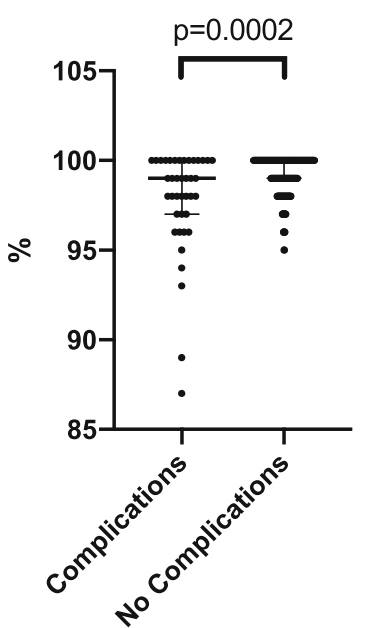

Fig. 3 Comparison of emergence conditions between complications versus no complications groups by a MAC, b end-tidal $\mathrm{CO}_{2}$ (etCO $)_{2}$, (C) $\mathrm{O}_{2}$ Saturation (Sat) before and (D) $\mathrm{O}_{2}$ Sat after extubation

Anesthetic depth did not appear to impact complications at the time of extubation MAC (1.33(1.07-1.71) vs $1.50(1.22-1.83, p=0.1002)$, nor did etCO 2 (51.5(44.3$58.5)$ vs 50.0 (43.0-57.0), $p=0.3352$ ) (Fig. 3a \& b). However, patient percent $\mathrm{O}_{2}$ saturation levels are significantly lower for the complication group compared to the no complications group at 5 mins before deep extubation (99.0(97.3-100) vs 100 (99.0-100), $p=0.0023$ ) (Fig. 3c).

The time from deep extubation to leaving the OR was longer, at $12.0(9.00-14.8)$ mins, in the complications group compared to $9.00(7.00-13.0)$ mins in the no complications group ( $p=0.0098)$ (Fig. 4a). The time to eye opening was also longer in the complications group than the no complications group (15.0(9.00-21.0) vs 18.0(13.3-25.0), $p=0.0036$ ) (Fig. 4b). The total intraoperative opioid use and muscle relaxant and reversal use are not significantly different between the two groups (Table 1).

\section{Discussion}

In this study, $13 \%$ of adult patients (40 out of 300 ) had at least one or more respiratory complications with deep extubation. This is within range of a previous publication by Kim and colleagues in which one group that 


\section{A Time Out of OR}

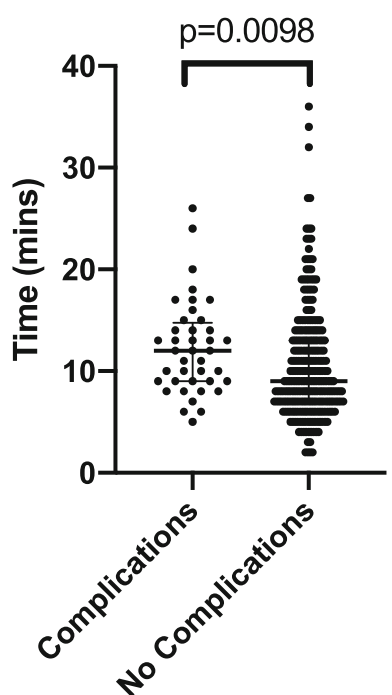

\section{B Time to Eye Opening}

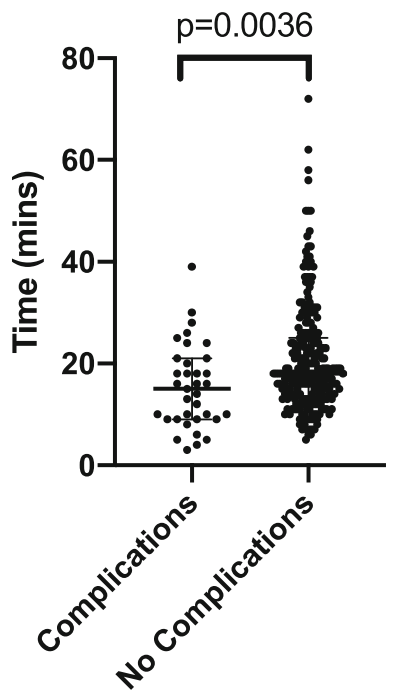

Fig. 4 Comparison of emergence times between complications versus no complications groups from end of surgery to a time out of OR and from extubation to $\mathbf{b}$ time to eye opening

received desflurane had a $48 \%$ complications rate (12 out of 25 patient) while the other group that received desflurane with remifentanil had a $3.4 \%$ complication rate (1 out of 29 patients) [10]. It is also consistent with Fan et al's report, where percentage of patient with airway complications ranges from 12 to $37.5 \%$ [11]. An important difference between ours and prior studies is how respiratory complications are defined. For example, whereas Kim et al's defined complications as coughing and breath holding, we expanded the criteria to capture additional complications, including significant desaturation, laryngospasm, stridor, bronchospasm and reintubation, that could also influence the success of deep extubation. It is worth noting that all of these complications were easily corrected by the anesthesia providers in our study with no need for drastic interventions such as reintubation. However, our data also showed that patients who had complications with deep extubation tended to stay longer in the OR compared with patients who did not.

It is well understood that deep extubation can minimize adverse hemodynamic reflexes in appropriate situations [12]. Nonetheless, many anesthesiologists are reluctant to perform deep extubation in adults because of concerns for potential respiratory complications [5]. The present study indicates that deep extubations in adults is likely safer than in the pediatric population. Our airway complication rate of $13 \%$ in adult patients is significantly lower than the $40 \%$ complication rate $(64$ out of 159 patients) reported in a recent meta-analysis of pediatric patients [13]. While it is possible that patient selection and provider difference account for the lower rate; it is also conceivable that the pediatric airway is more irritable and sensitive to stimulation than the adult airway [14].

Table 1 Comparison of intraoperative dose of medications. Drug name (dosing unit) are listed in the left column. Data are expressed as median (q1-q3)

\begin{tabular}{llll}
\hline Drugs & $\begin{array}{l}\text { Complications } \\
(\boldsymbol{n}=\mathbf{4 0})\end{array}$ & $\begin{array}{l}\text { No Complications } \\
(\boldsymbol{n}=\mathbf{2 6 0})\end{array}$ & $\begin{array}{c}\boldsymbol{P} \text {-Value } \\
\text { Fentanyl (mcg) }\end{array}$ \\
Remifentanil (mg) & $100(0.0-100.0)$ & $100(0.0-100.0)$ & 0.3674 \\
Morphine (mg) & $0.580(0.15-0.973)$ & $0.435(0.100-0.960)$ & 0.3133 \\
Hydromorphone (mg) & $0.0(0.0-2.0)$ & $0.0(0.0-2.0)$ & $>0.9999$ \\
Rocuronium (mg) & $0.200(0.00-0.900)$ & $0.00(0.00-0.500)$ & 0.3374 \\
Succinylcholine (mg) & $10.0(0.00-10.0)$ & $10.0(0.00-10.0)$ & 0.5999 \\
Neostigmine (mg) & $100(0.00-100)$ & $80.0(0.00-100)$ & 0.6332 \\
\hline
\end{tabular}


Present study suggests that patient selection plays an integral part in the success of endotracheal deep extubations. Our anesthesia providers selected patients for deep extubations per clinical discretion without predetermined criterion. Overwhelmingly, the patients selected had easy airway placement based on the Cormack and Lehane's Grade as only 1 patient out of 300 had a grade 4 view, which is a probable factor contributing to an overall complications rate near the lower limits of previously published ranges [10, 11]. On the flip side, our data also shows that when the provider chose to deep extubate patient with lower $\mathrm{O}_{2}$ saturation levels 5 mins prior to extubation, these patients are more likely to have significant airway complications. Our results suggest that higher BMI patients are less likely to tolerate deep extubations. We observed a statistically significant correlation between higher BMI and likelihood of complications during deep extubation. The median BMI in the complications group was 30 while the median BMI in the no complications group was 26 . Obesity has been shown to worsen oxygenation through several mechanisms, including increased intraabdominal pressure and atelectasis [15-17]. Whether an isolated elevated BMI is a causal factor for complications during deep extubations will need further investigation.

The depth of anesthesia suitable for a smooth deep extubation is primarily based on the MAC of inhaled anesthetics. Previous studies suggested that extubation could be performed at an inhaled anesthetic level as low as 1 MAC $[2,11,18-20]$. Some of the differences in MAC levels were likely due to variations in adjuvant opioid use, because opioid medications have been shown to minimize coughing and various extubation related adverse events [21, 22]. Here, we allowed the providers to freely decide the type and amount of opioid use appropriate for practice and did not observe a significant difference in the amount of opioid used in the complications versus no complications groups.

There were several limitations to this study. Firstly, this is a single-center prospective study, and the anesthesiologists were not and could not be blinded to the treatment technique. Secondly, there is also significant selection bias in the study, as no patients with history of difficult airway underwent deep extubation. Thirdly, other than the deep extubation technique, the anesthetic management was not standardized. However, this is a reality of every day anesthesia practice, irrespective of the extubation technique. Lastly, an experienced anesthesia provider remained with each patient until an adequate control of the airway was achieved, which could have contributed to the low incidence rate of complications. Moving forward, we hope our data can facilitate a more informed calculation of sample size for future studies comparing the complication rate of deep versus awake extubation in adults. As expected, time to leaving the OR was higher in the complication group, however, the general question about differences in operating room turnover times between deep and traditional extubation techniques is beyond the scope of this study. Finally, there are probably many different ways of performing a deep extubation and further studies should be done to fine tune this technique.

\section{Conclusions}

Our findings demonstrate that deep extubation in adults is associated with a relatively low complication rate. Furthermore, high BMI and low $\mathrm{O}_{2}$ saturation levels preextubation are associated with increased complications. We acknowledge that deep extubation should not be performed in patients with a known of history of difficult airway or aspiration risk and should always be performed by experienced providers after careful assessment. However, our experience does support deep extubation as a feasible and safe option in appropriate clinical circumstances.

\section{Abbreviations}

ASA PS: American Society of Anesthesiologists Physical Status; BMI: Body Mass Index; FiO2: Fraction of inspired Oxygen; GA: General Anesthesia; IRB: Institutional Review Board; MAC: Minimum Alveolar Concentration; MEEl: Massachusetts Eye and Ear Infirmary; PACU: Post Anesthesia Care Unit; $\mathrm{SPO}_{2}$ : Saturation of Peripheral Oxygen

\section{Acknowledgments}

Xinling Xu, Statistician. Department of Anesthesiology, Perioperative and Pain Medicine Brigham and Women's Hospital, Harvard Medical School, 75 Francis St, Boston, MA 02115 USA.

\section{Disclosures \\ None.}

\section{Authors' contributions}

Author: J.J. Contribution: J.J.: supervision, project administration, validation, formal analysis, investigation, data curation, writing-original draft, writingreview \& editing. Attestation: J.J. approved the final manuscript and attests to the integrity of the case report presented in this manuscript. Conflicts of Interest: none. Author: M.C. Contribution: M.C.: Conceptualization, methodology, investigation, supervision, data curation, validation, writing-original draft, and writing- review \& editing. Attestation: M.C. approved the final manuscript and attests to the integrity of the study presented in this manuscript. Conflicts of Interest: None. Author: A.C. Contribution: A.C.: investigation, data curation, and validation. Attestation: A.C. approved the final manuscript and attests to the integrity of the study presented in this manuscript. Conflicts of Interest: None Author: M.X. Contribution: M.X.: data analysis, writing-original draft, and writing- review \& editing. Attestation: M.X. approved the final manuscript and attests to the integrity of the study presented in this manuscript. Conflicts of Interest: None. Author: J.G. Contribution: J.G.: Supervision, investigation, data curation, validation, interpretation, writing-original draft, writing- review \& editing. Attestation: J.G. approved the final manuscript and attests to the integrity the study presented in this manuscript. Conflicts of Interest: none. Author: J.E.B. Contribution: J.E.B.: Conceptualization and methodology. Attestation: J.E.B. approved the final manuscript and attests to the integrity of the study presented in this manuscript. Conflicts of Interest: None. Author: A.A.M. Contribution: A.A.M.: Conceptualization, methodology, investigation, data curation, validation, formal analysis, writing-original draft, writing- review \& editing, supervision, project administration, and funding acquisition. Principal Investigator. Attestation: A.A.M. approved the final manuscript and attests to the integrity of the study presented in this manuscript. 
Funding

None.

\section{Availability of data and materials}

The datasets used and/or analyzed during the current study available from the corresponding author on reasonable request.

\section{Ethics approval and consent to participate}

Approved by the Institutional Review Board (IRB) of Massachusetts Eye and Ear Infirmary (MEEI), Boston, Massachusetts (\#1047249). The study was conducted in accordance with all rules and regulations laid out by the IRB and human studies committee. Written informed consent was waived by MEEI IRB.

\section{Consent for publication}

Not Applicable.

\section{Competing interests}

The authors do not have any competing interests.

\section{Author details}

${ }^{1}$ Department of Anesthesiology, Massachusetts Eye and Ear, 243 Charles St, Boston, MA 02114, USA. ${ }^{2}$ Harvard Medical School, Boston, MA 20114, USA.

${ }^{3}$ Clinica El Pinar, Km 2 Anillo vial Floridablanca - Girón, Ecoparque

Empresarial Natura Torre 2 piso 1 y 2, Piedecuesta, Colombia.

Received: 31 July 2020 Accepted: 20 October 2020

Published online: 29 October 2020

\section{References}

1. Valley RD, Ramza JT, Calhoun P, Freid EB, Bailey AG, Kopp VJ, Georges LS. Tracheal extubation of deeply anesthetized pediatric patients: a comparison of isoflurane and sevoflurane. Anesth Analg. 1999;88(4):742-5.

2. Valley RD, Freid EB, Bailey AG, Kopp VJ, Georges LS, Fletcher J, Keifer A. Tracheal extubation of deeply anesthetized pediatric patients: a comparison of desflurane and sevoflurane. Anesth Analg. 2003;96(5):1320-4 table of contents.

3. Irwin RS. Complications of cough: ACCP evidence-based clinical practice guidelines. Chest. 2006;129(1 Suppl):54S-8S

4. Fagan C, Frizelle HP, Laffey J, Hannon V, Carey M. The effects of intracuff lidocaine on endotracheal-tube-induced emergence phenomena after general anesthesia. Anesth Analg. 2000;91(1):201-5.

5. Daley MD, Norman PH, Coveler LA. Tracheal extubation of adult surgical patients while deeply anesthetized: a survey of United States anesthesiologists. J Clin Anesth. 1999;11(6):445-52.

6. Patel RI, Hannallah RS, Norden J, Casey WF, Verghese ST. Emergence airway complications in children: a comparison of tracheal extubation in awake and deeply anesthetized patients. Anesth Analg. 1991;73(3):266-70.

7. Pounder DR, Blackstock D, Steward DJ. Tracheal extubation in children: halothane versus isoflurane, anesthetized versus awake. Anesthesiology. 1991;74(4):653-5.

8. Koga K, Asai T, Vaughan RS, Latto IP. Respiratory complications associated with tracheal extubation. Timing of tracheal extubation and use of the laryngeal mask during emergence from anaesthesia. Anaesthesia. 1998;53(6): 540-4.

9. von Ungern-Sternberg BS, Davies K, Hegarty M, Erb TO, Habre W. The effect of deep vs. awake extubation on respiratory complications in high-risk children undergoing adenotonsillectomy: a randomised controlled trial. Eur J Anaesthesiol. 2013;30(9):529-36.

10. Kim MK, Baek CW, Kang H, Choi GJ, Park YH, Yang SY, Shin HY, Jung YH, Woo YC. Comparison of emergence after deep extubation using desflurane or desflurane with remifentanil in patients undergoing general anesthesia: a randomized trial. J Clin Anesth. 2016;28:19-25.

11. Fan Q, Hu C, Ye M, Shen X. Dexmedetomidine for tracheal extubation in deeply anesthetized adult patients after otologic surgery: a comparison with remifentanil. BMC Anesthesiol. 2015;15:106.

12. Jaffe RA, Schmiesing CA, Golianu B. Anesthesiologist's manual of surgical procedures. 5th ed. Philadelphia: Lippincott Williams \& Wilkins; 2014.1 online resource.

13. Koo CH, Lee SY, Chung SH, Ryu JH. Deep vs. Awake Extubation and LMA Removal in Terms of Airway Complications in Pediatric Patients Undergoing
Anesthesia: A Systemic Review and Meta-Analysis. J Clin Med. 2018;7:353. https://doi.org/10.3390/jcm7100353

14. Peat JK, Gray EJ, Mellis CM, Leeder SR, Woolcock AJ. Differences in airway responsiveness between children and adults living in the same environment: an epidemiological study in two regions of New South Wales. Eur Respir J. 1994;7(10):1805-13.

15. Eichenberger A, Proietti S, Wicky S, Frascarolo P, Suter M, Spahn DR, Magnusson L. Morbid obesity and postoperative pulmonary atelectasis: an underestimated problem. Anesth Analg. 2002;95(6):1788-92 table of contents.

16. Pelosi P, Gregoretti C. Perioperative management of obese patients. Best Pract Res Clin Anaesthesiol. 2010;24(2):211-25.

17. Lang LH, Parekh K, Tsui BYK, Maze M. Perioperative management of the obese surgical patient. Br Med Bull. 2017;124(1):135-55.

18. Inomata $\mathrm{S}$, Yaguchi $\mathrm{Y}$, Taguchi $\mathrm{M}$, Toyooka H. End-tidal sevoflurane concentration for tracheal extubation (MACEX) in adults: comparison with isoflurane. Br J Anaesth. 1999;82(6):852-6.

19. Shen X, Hu C, Li W. Tracheal extubation of deeply anesthetized pediatric patients: a comparison of sevoflurane and sevoflurane in combination with low-dose remifentanil. Paediatr Anaesth. 2012;22(12):1179-84.

20. Hu C, Yu H, Ye M, Shen X. Sevoflurane in combination with remifentanil for tracheal extubation after otologic surgery. Am J Health Syst Pharm. 2014; 71(13):1108-011.

21. Mignat $C$, Wille $U$, Ziegler A. Affinity profiles of morphine, codeine, dihydrocodeine and their glucuronides at opioid receptor subtypes. Life Sci. 1995:56(10):793-9.

22. Yarmush J, D'Angelo R, Kirkhart B, O'Leary C, Pitts MC 2nd, Graf G, Sebel P, Watkins WD, Miguel R, Streisand J, et al. A comparison of remifentanil and morphine sulfate for acute postoperative analgesia after total intravenous anesthesia with remifentanil and propofol. Anesthesiology. 1997;87(2):235-43.

\section{Publisher's Note}

Springer Nature remains neutral with regard to jurisdictional claims in published maps and institutional affiliations.
Ready to submit your research? Choose BMC and benefit from:

- fast, convenient online submission

- thorough peer review by experienced researchers in your field

- rapid publication on acceptance

- support for research data, including large and complex data types

- gold Open Access which fosters wider collaboration and increased citations

- maximum visibility for your research: over $100 \mathrm{M}$ website views per year

At BMC, research is always in progress.

Learn more biomedcentral.com/submissions 